\title{
RELEVÂNCIA DO CONCEITO BIM PARA INCORPORADORAS E/OU CONSTRUTORAS DO SETOR IMOBILIÁRIO
}

\author{
Sumaia Gonçalves $^{(1)}$, Flavia Souza ${ }^{(1)}$ \\ (1) Escola Politécnica da USP, São Paulo
}

\begin{abstract}
Resumo
Métodos emergentes voltados à gestão estratégica têm oferecido a possibilidade de avaliar a vantagem competitiva das organizações a partir da perspectiva dos seus recursos estratégicos, incluindo o conhecimento. No contexto da implementação do conceito BIM em empresas incorporadoras e/ou construtoras do mercado imobiliário brasileiro, torna-se fundamental a tangibilização dos benefícios desde o nível imediato chegando aos benefícios de longo prazo. Nesse sentido, este trabalho tem como objetivo evidenciar como a inovação caracterizada pela implementação do conceito BIM pode trazer vantagem competitiva para empresas do Mercado Imobiliário, na medida que os modelos de informações possibilitam, entre outros, acesso à base significativa de informações, as quais devem ser disponibilizadas, estruturadas e padronizadas, de modo a subsidiar o processo de tomada de decisão ao longo do ciclo de vida do empreendimento. Para tanto, o método de pesquisa contempla a revisão bibliográfica sobre implementação do conceito BIM e estudo de caso em empresa Incorporadora atuante no Mercado Imobiliário Brasileiro com análises referentes ao viés estratégico da implementação do conceito BIM a partir do Resource Based View (RBV).
\end{abstract}

\section{Introdução}

BIM é um conjunto de tecnologias, processos e políticas que possibilitam que todos os interessados - agentes atuantes no ciclo do empreendimento, tenham condições de colaborativamente, desenvolver, construir e operar o empreendimento em todo seu ciclo de vida [11].

Nos últimos anos o BIM tem sido um tópico em ascendência na indústria da arquitetura, engenharia, construção e operação. Um estudo feito pela McGraw Hill Construction [6] e [7] mostra que na Austrália e na América do Norte o principal benefício em curto prazo do uso do BIM é da redução de erros e omissões, e o maior benefício em longo prazo observado pelas empresas Australianas é o de redução da duração total do projeto, enquanto que na América do Norte a repetição de negócios foi tida como maior benefício em longo prazo. A redução de erros e omissões se deve ao fato de que o modelo integrado facilita o planejamento da obra, o que permite observar incompatibilidades entre os projetos na etapa de desenvolvimento, mitigando 
improvisos no canteiro. A redução da duração total do projeto é mais bem observada em companhias que já possuem alguma experiência com o uso do BIM, pois as bibliotecas criadas facilitam o detalhamento e execução do projeto. Segundo McGraw Hill Construction [7], o aumento do conhecimento sobre o valor do BIM que clientes estão tendo influenciou a repetição de negócios com um crescimento de $49 \%$ em 2012, ou seja, os clientes buscavam empresas com as quais eles já haviam tido experiências com o uso do BIM.

A tendência é de que o setor público e o privado continuem no investimento da inovação na construção civil especificamente na difusão e uso do BIM como ferramenta chave para o desenvolvimento de empreendimentos e integração dos agentes da cadeia da construção. Logo, se torna fundamental o estudo na área para identificar pontos de melhorias, gargalos presentes que dificultam sua disseminação e consequente adoção; bem como visando aperfeiçoar tal método. Especificamente no Brasil, as dificuldades na adoção do BIM entre os agentes da cadeia produtiva repercutem em atraso tecnológico no setor da construção civil e consequentemente redução no potencial competitivo e de diferenciação entre os envolvidos no ciclo da produção do empreendimento. Este artigo buscará evidenciar que o conceito Building Information Modeling ou Modelagem da Informação da Construção não se trata de uma ferramenta, mas uma metodologia de produção, gerenciamento, integração e controle. $\mathrm{Na}$ cadeia produtiva da construção civil, ela é empregada para desenvolver e gerir informações e dados ao longo de toda a vida útil do empreendimento, portanto faz-se fundamental evidenciar como o conceito BIM possui potencial para revolucionar produtos, sistemas, processos e métodos, e por fim, estratégias para empresas incorporadoras e/ou construtoras.

Partindo do pressuposto de que o conceito BIM agrega valor à estratégia competitiva das organizações parte da industria da construção civil, neste artigo as referências e discussões sobre estratégia estão pautadas na Visão Baseada em Recursos (RBV). A definição de estratégia a partir do RBV envolve o equilíbrio entre a exploração dos recursos existentes e o desenvolvimento de novos recursos organizacionais [9]. Os recursos podem envolver as capacidades, as habilidades gerenciais, os processos organizacionais, o conhecimento, a marca, a informação sobre clientes, a cultura organizacional, os financeiros ou outros atributos controlados pela empresa que quando articulados de forma peculiar apresentam oportunidades estratégicas [3].

O modelo VRIO é aplicável para analisar forças e fraquezas internas da empresa e identificar quais são os seus recursos estratégicos. São quatro questões que devem ser analisadas referente a todos os recursos da organização: Valor, Raridade, Imitabilidade e Organização.

Isto posto, pode-se observar que diferentemente das teorias clássicas que analisam o ambiente externo e depois sugerem uma estratégia, a visão baseada em recursos foca a questão da estratégia internamente, quando os recursos internos da empresa são o foco para desenvolver essas estratégias. Nesse quesito é possível afirmar que o RBV se apresenta como inovação, uma visão de "dentro para fora" indo contra a corrente das visões mais clássicas que existiam na época. Segundo o RBV, o desempenho de uma organização para ser competitiva está fortemente associado aos recursos que essa organização possui e administra.

\section{Referencial Teórico}

BIM pode ser considerada uma inovação a qual tende a aumentar substancialmente a produtividade do setor pois possibilita que arquitetos, engenheiros, mestres de obra e gestores 
trabalhem em conjunto, facilitando tarefas de compatibilização e detecção de erros ainda nas fases iniciais de projeto [4].

Pode-se perceber atualmente que as organizações passam a utilizar novas técnicas, tecnologias, padrões e paradigmas que ajudam alcançar eficiência e eficácia em seus processos, produtos e serviços e assim atender às necessidades individuais dos seus clientes. Aliada a esta mudança de foco, as organizações se deparam com a necessidade de ampliar a visão do negócio adaptando aos seus departamentos. Nota-se então, que dentro das organizações, para acompanhar as mudanças e expectativas do mercado, a antiga visão departamental (ou funcional) deveria evoluir para uma visão mais aperfeiçoada, apurada, que evitasse vários problemas que a conformação departamental traz consigo [10].

Essa evolução está levando as organizações à constituírem uma nova leitura de processos, que permite à organização visualização mais detalhada e, ao mesmo tempo, abrangente do seu negócio. Frente a essas mudanças, as tecnologias de modelagem de negócios posicionam-se como importante mecanismo para acompanhamento dos processos e retroalimentações, permitindo solucionar muitos problemas desde a concepção, podendo reformular o esquema estrutural da empresa, sem olvidar o fortalecimento e sustentabilidade das ações estratégicas das corporações. Neste viés o conceito BIM se insere como ferramenta auxiliar determinante ao sucesso da atividade do século 21.

Quando se trata de modelo de negócio é fundamental lembrar que este descreve a lógica de criação, entrega e captura de valor por parte de uma organização. Ou seja, um modelo de negócio determina o produto ou serviço que uma organização irá produzir ou fornecer, já o método de produção define seu público alvo e suas fontes de receita.

Os acadêmicos em estratégia têm usado a noção de modelo de negócios também para se referirem à lógica das empresas, como elas operam e criam valor para seus stakeholders.

$\mathrm{O}$ modelo de negócios consiste em ferramenta conceitual que contém conjunto de elementos e suas relações que expressam a lógica dos negócios de uma dada empresa. Portanto, o modelo de negócios caracteriza-se como representação abstrata dos elementos-chave da estratégia de negócio: o que será vendido (proposta de valor), a quem será comercializado, quais são os processos essenciais para o desenvolvimento do produto/serviço (incluindo a estrutura de custos) e como ocorrerá a interação mercadológica entre empresa e clientes [8].

\section{Método}

O trabalho relatado neste artigo faz parte do desenvolvimento da pesquisa de mestrado em desenvolvimento no Programa de Mestrado Profissional do Departamento de Engenharia de Construção da Escola Politécnica da USP, Construinova. O método de pesquisa utilizado neste artigo é qualitativo e conduzido por meio de Estudo de Caso único.

Buscou-se a metodologia estudo de caso pois, trata-se de uma investigação empírica que investiga um fenômeno contemporâneo e em seu contexto de vida real [12].

A estrutura do Estudo de Caso contempla a revisão bibliográfica acerca da implementação do conceito de modelagem da informação e também sobre estratégia, visando embasar a discussão sobre como o uso das informações geradas a partir dos Modelos de Informações podem agregar valor à estratégia competitiva da Incorporadora e Construtora Brasileira estudada. A coleta de dados nesta empresa é realizada por meio de entrevistas e também observações coletadas pela 
primeira autora, sendo esta diretamente responsável pelo processo de implementação do conceito BIM.

\section{Estudo de Caso}

O presente artigo apresenta parte de estudo de caso feito em empresa do setor imobiliário brasileiro, sendo Incorporadora e Construtora, podendo ser classificada com empresa de grande envergadura quanto ao poder de atuação em seu nicho. O estudo trata da implantação BIM na referida empresa, especificamente na Construtora, iniciando pelo departamento da Engenharia. A implantação visou propósitos tecnológicos e estatégicos empresariais.

Detectado o cunho estratégico para implantação da nova metodologia, os preceitos da Visão Baseada em Recursos (RVB) são aplicados para as análises, partindo do pressuposto de que podem ajudar as empresas a se diferenciar das demais e manter tal diferencial ao longo do tempo. Caso a empresa apresente recursos que criem valor e sejam raros, difíceis de serem imitados, e esta puder se organizar para explorá-los, esses recursos podem constituir fonte de vantagem competitiva sustentável [2].

\subsection{Modelo de negócios}

Sob tais reflexões apresentadas, a gestão da implantação BIM na empresa estudada propôs a reanalise do modelo de negócios atual, visando atuar em novas propostas uma vez percebido que a metodologia BIM se insere rumo ao mesmo propósito estratégico. Isto posto, entendeuse que a abordagem via Canvas seria a mais apropriada por facilitar a visualização do impacto estratégico da implementação do BIM. Com base em análises documentais estratégicas da empresa e entrevista a parte do corpo da gestão empresarial, compilou-se o quadro canvas estampado na figura 1.

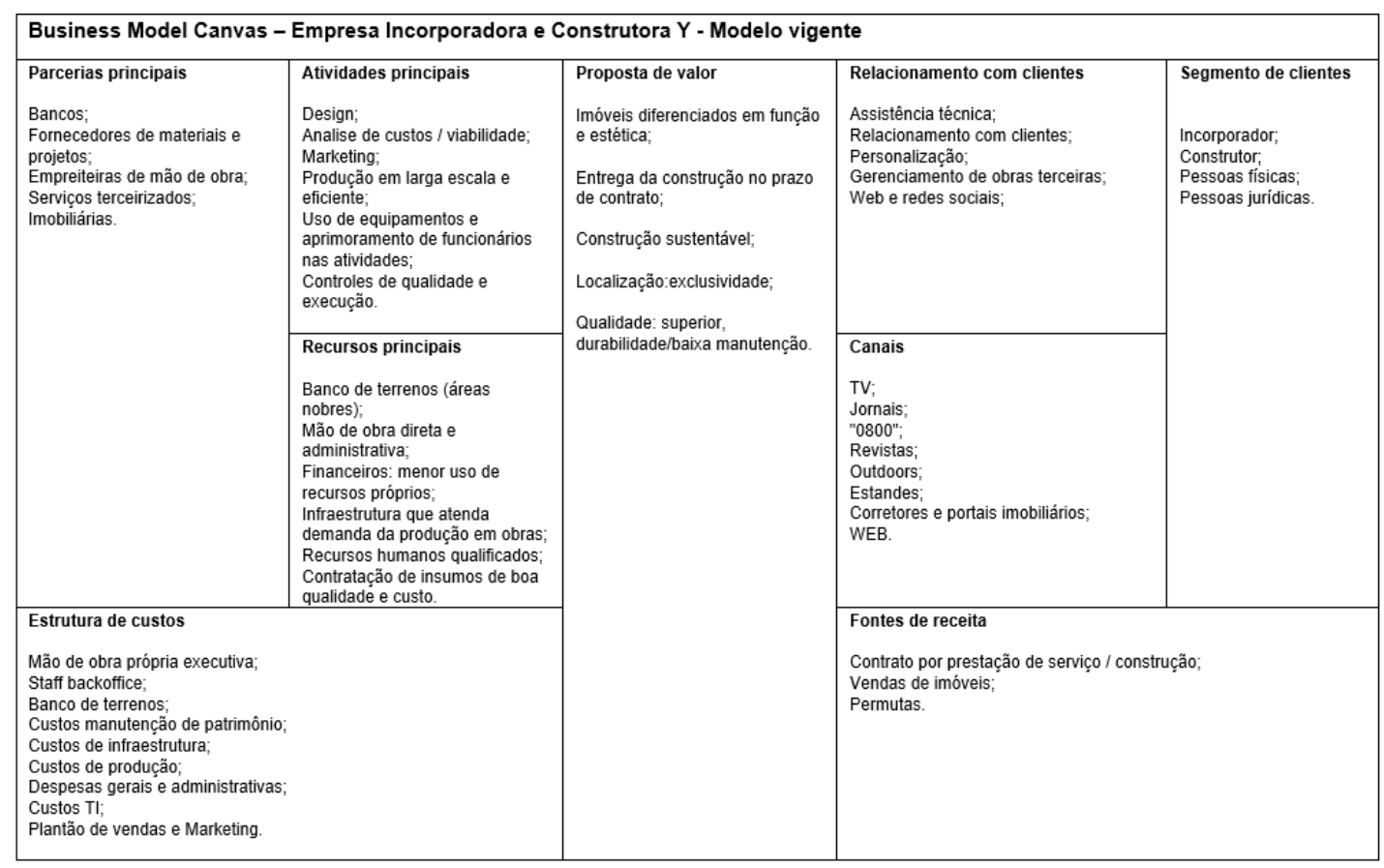

Figura 1: Business Model Canvas Modelo Vigente (2019). Fonte: Autora. 
Ressalta-se que a identificação e compreensão do modelo de negócio é parte fundamental para analisar trajetória, replanejar processos e produtos, e buscar novos rumos compatíveis com as exigências do século 21.

Primeiramente, faz-se necessário definir inovação de produto como sinônimo de inovação tecnológica e inovação estratégica como sinônimo de mudanças de modelos de negócios.

J. Butler [5] advoga a existência de grande relação entre inovação tecnológica e a administração estratégica corporativa da empresa.

Nesse sentido, BIM pode ser considerado como inovação estratégica, e não como uma mera solução de gestão, relacionando-se ao posicionamento empresarial voltado à produtividade, à qualidade e à transparência. Como exemplo, o processo BIM tem potencial de redução a quase zero das perdas de materiais de instalação, quais custam de $12 \%$ a $18 \%$ do total da obra costumeiramente.

Ainda, a título explicativo, BIM pode ser decisivo para que a empresa consiga vencer concorrências e contratar novas construções incorporadas por terceiros. Logo, o método BIM afigura-se meio de incremento substancial de produtividade ao setor da construção, no qual o contratante consegue enxergar de forma clara e inequívoca o plano de ataque e o planejamento da obra, inclusive com os quantitativos de materiais e serviços, garantindo aderência ao custo orçado e atendimento aos almejados prazos acordados.

Portanto, a partir do entendimento de que o BIM tem capacidade de melhorar a qualidade das obras, reduzir desperdícios, dar mais transparência nas contas públicas ou privadas, mais ênfase no planejamento, confiabilidade nas estimativas de custos e cumprimentos dos prazos, bem como promover menor incidência de erros e imprevistos tanto nas obras quanto na redução de aditivos ao proporcionar aumento de confiabilidade das informações uma vez estas se apresentarem de forma clara e indubitável, pode-se caracteriza-lo como estratégico.

\subsection{Enquadramento: inovação estratégica}

A caracterização como inovação estratégica se impõe quando entendido como fator de competitividade, pela redução das margens de riscos e de perdas, pela visualização fidedigna dos percursos do empreendimento.

Neste sentido, com base no EIR (employer information requirement) os autores Ammar Dakhil, Jason Underwood e Mustafa Al Shawi [1], listaram competências BIM e as analisaram quanto percepção de diferentes clientes contratantes da metodologia, sendo estes: clientes públicos, privados ou com atuação em ambas searas, como no caso de universidades. Ressaltou-se ainda dentro do grupo dos clientes privados o nicho de atuação, podendo ser local, varejista ou atuante especificamente no mercado imobiliário.

Quanto às competências, habilidades na metodologia BIM de relevância, foram elencadas: definição de gerenciador de dados, definições de padrões, tipos de tecnologias BIM utilizadas, bem como o entendimento profundo da metodologia. Tais aspectos foram eleitos pelos clientes entrevistados como competências predecessoras fundamentais para que clientes possam liderar suas implantações BIM.

O referido artigo ainda ressalta veementemente o importante papel da liderança do cliente na implementação da metodologia, sendo este ainda, o principal agente validador dos produtos gerados durante a implementação BIM. Com base no estudo, pode-se entender que no intuito de evidenciar e motivar a implementação de nova metodologia tão impactante, faz-se de extrema relevância destacar a importância de desenvolver relacionamento entre competências BIM e benefícios BIM desejáveis, a fim de ajudar os clientes proponentes a investir apenas em 
competências valiosas que serão mais relevantes para os benefícios BIM selecionados. Trazendo estes conceitos para o estudo de caso, entende-se a pertinência da compreensão do que se quer atingir com o objetivo de uma implantação metodológica tão impactante processual e tecnologicamente. Por tal, a gestão da implantação trouxe o seguinte questionamento aos gestores-chaves participantes do processo de implantação: Qual o valor da sua entrega para o atual modelo de negócio da empresa Y? Qual seu principal produto / contribuição de entrega ao fluxo da produção do empreendimento?

Tabela 1: Entrevista quanto ao valor de entrega percebido pelos gestores-chaves. Fonte: Autora

\begin{tabular}{|c|c|c|}
\hline Entrevistados & $\begin{array}{c}\text { Qual o valor da sua entrega - departamento } \\
\text { - para o atual modelo de negócio da } \\
\text { empresa Y? }\end{array}$ & $\begin{array}{l}\text { Qual seu principal produto/contribuição de } \\
\text { entrega - departamento - ao fluxo da } \\
\text { produção do empreendimento? }\end{array}$ \\
\hline $\begin{array}{l}\text { Gerente de Orcamentose } \\
\text { Planejamento }\end{array}$ & $\begin{array}{l}\text { Viabilizar negocios imobiliários } \\
\text { financeiramente para empresa. }\end{array}$ & $\begin{array}{l}\text { O maior ganho é o tempo para extrair o } \\
\text { quantitativo. } \\
\text { Após implantaça do BrM em sua plenitude } \\
\text { podemos reduzir o tempo para orçamento } \\
\text { em } 40 \%\end{array}$ \\
\hline Gerente de Projetos & $\begin{array}{l}\text { Disponibilizar projetos com alto nivel de } \\
\text { qualidade (atendimento de diretrizes e } \\
\text { boas praticas consolidadas pela empresa) } \\
\text { em tempo adequado. Busca de solup̧es e } \\
\text { materiais inovadores. }\end{array}$ & $\begin{array}{l}\text { Projetos assertivos, em tempo adequado } \\
\text { com soluçőes otimizadas em custo e } \\
\text { execuçăo, mantendo o foco em inovaçăo. }\end{array}$ \\
\hline Gerente de Produto & $\begin{array}{l}\text { Produto imobiliário adequado ao público } \\
\text { alvo definido pela empresa, dentro do } \\
\text { custo e valor de venda compativel com o } \\
\text { mercado de atuaçăo. Produtos } \\
\text { diferenciados. }\end{array}$ & $\begin{array}{c}\text { Inicia a cadeia de produção à partir da } \\
\text { passadem de terreno, alimentando todas as } \\
\text { areas de interface para o desenvolvimento } \\
\text { do produto do final da concepsão à entrega } \\
\text { final da obra. }\end{array}$ \\
\hline $\begin{array}{l}\text { Gerente de Qualidade e } \\
\text { Desenvolvimento } \\
\text { Tecnologico }\end{array}$ & $\begin{array}{c}\text { Obras com execução adequadas aos } \\
\text { procedimentos executivos estabelecidos e } \\
\text { consolidados da empresa e departamentos } \\
\text { com processos aderentes aos } \\
\text { procedimentos definidos e adequados às } \\
\text { normas de referência. } \\
\text { Quanto ao Desenvolvimento Tecnologico, } \\
\text { buscar soluçóes de materiais e novos } \\
\text { sistemas construtivos, com custo e } \\
\text { desempenho adequado ao empreendimento } \\
\text { e/ou padrōes da empresa. }\end{array}$ & $\begin{array}{l}\text { Obras com execução e especificaçoes } \\
\text { adequadas que garantam qualidade e } \\
\text { atendimentos às normas e com custo e } \\
\text { desempenho adequado. }\end{array}$ \\
\hline
\end{tabular}

Prioritário às fases de análises, deve-se entender o que de fato é valor de entrega para cada área permeada na implantação da nova metodologia, para que com estas respostas seja possível verificar como BIM agrega valor a empresa estudada.

A análise dos dados denota que apesar da apuração parcial, pois até a finalização da compilação, as diretorias não haviam se pronunciado quanto ao questionamento; as respostas estão diretamente ligadas aos produtos colhidos na implantação bem-sucedida do BIM. Ainda, as gerências consultadas, parte diretamente operante dos sistemas e trâmites cotidianos, identificam como valor os produtos resultantes, tangíveis na metodologia BIM. Com tal base de dados, podemos conjecturar alguns pontos que se seguem:

\section{- Gerente de Orçamentos e Planejamento:}

Aponta como principal valor de entrega a necessidade de viabilizar negócios para empresa financeiramente e como maior contribuição elaboração de orçamentos em tempo curto, ou seja, agilidade nas simulações de custos para empreendimentos. Após implantação do conceito em 
sua área, enxerga factível o benefício via metodologia BIM. Em tempos de grande competição entre empresas do setor, agilidade, de fato pode ser fator determinante de performance. Ressalte-se quando o termo agilidade é colocado, não se trata apenas de rapidez na execução de tarefas, mas celeridade conciliado à assertividade. Sim, se faz necessários números rápidos, porém com grande grau de precisão.

Saliente-se o entrevistado não focou na outra área de atuação que gerencia, a área de Planejamento de obras; cuja pode ainda ser de grande relevância aos seus olhos e das demais equipes, à medida em que os benefícios das modelagens para simulações de ataque de obras, atrelamento com cronogramas de contratações e físico, bem como o próprio estudo da evolução do canteiro, se mostrem palpáveis e de grande utilidade.

\section{- Gerente de Projetos:}

Qualidade e prazo foram os grandes temas abordados quando se questiona sobre valor da área consultada. No quesito qualidade, refere-se ao atendimento de diretrizes padrão da empresa em questão e a previsão de soluções construtivas que retratem as boas práticas difundidas pelas empresas e instituições admiradas pelo setor. Pode-se entender ainda que são almejados projetos compatibilizados, com qualidade de suas informações, em "tempo adequado". Entende-se este termo como cumprimento de cronogramas preestabelecidos junto aos shareholders e stakeholders. Proposituras de soluções otimizadas quanto a custo e execução também são consideradas como grande contribuição. Neste momento, verifica-se a preocupação em manter-se aderente ao orçamento comprometido de obras e a busca por evitar percalços nas questões executivas durante evolução da obra. Ressaltou-se foco pela busca de soluções e materiais inovadores que tragam diferenciação para seus produtos. A área de projetos tem a incumbência de transformar aspectos estéticos em soluções efetivas para execução, desde a concepção de projetos, prototipagem e verificação de custos envolvidos. Com todas as provocações mencionadas dificilmente não se relaciona diretamente os benefícios da metodologia BIM com os grande anseios e percepções de valor nesta seara.

\section{- Gerente de Produto:}

A gestão reconheceu como valor primário a concepção de produto imobiliário, sendo este adequado ao público alvo definido pela empresa, atendendo custo e valor de venda compatível com o mercado de atuação. Concepção de Produtos diferenciados foi apresentada como a demanda da presidência. Atualmente, percebe-se anseio especial por inovação estética, principalmente das fachadas do produto imobiliário. Outro grande enfoque, é dado à concepção dos programas de área decoradas do condomínio em questão. Assinatura de decoradores e arquitetos renomados em âmbito internacional é mote de diferenciação para gestão consultada.

\section{- Gerente de Qualidade e Desenvolvimento Tecnológico:}

O valor agregado que a área objetiva entregar, são obras com execução adequadas aos procedimentos executivos estabelecidos e consolidados da empresa, bem como departamentos com processos aderentes aos procedimentos definidos e adequados às normas de referência. Quanto aos processos de Desenvolvimento Tecnológico, visam soluções de materiais e novos sistemas construtivos, com custo e desempenho adequado ao empreendimento e/ou padrões da empresa. Como principal produto / contribuição, o departamento entende que garantir especificações adequadas aos sistemas que se propõe e com desempenho previsto é o grande diferencial. Percebe-se a preocupação com a garantia das informações que gestam os processos 
nos canteiros e dentro dos departamentos da empresa, além da garantia de cumprimento de procedimentos.

\subsection{Análises}

Com o intuito de relacionarmos os anseios dos gestores entrevistados versus possíveis benefícios estratificáveis, referenciam-se alguns dos pontos exaltados na literatura sobre a temática BIM como sendo seus principais usos e potencialidades: Coordenação 3D, revisões de projetos diversas, revisitação em concepção de soluções, planejamento de sistemas de construções, analises e simulações de condições de terrenos, planejamento 4D, controle de custos, programação, análises estruturais e energéticas [7].

Numa análise dos valores apontados pelos gestores em comparação às possíveis conquistas advindas da utilização do BIM durante o ciclo de vida do empreendimento (retratadas pelas referências acima), é possível relacionar enfaticamente que a metodologia é capaz de auxiliar nas conquistas destes grandes indicadores de valor e qualidade. Abaixo quadro com analogias que denotam tal conjectura.

Tabela 2: Planilha percepção de valor versus potencialidades BIM. Fonte: Autoras

\begin{tabular}{|c|c|c|}
\hline Área de atuação & Percepção de valor & $\begin{array}{l}\text { Potencialidade BIM diretamente } \\
\text { relacionável }\end{array}$ \\
\hline $\begin{array}{l}\text { Gerente de Orçamentos e } \\
\text { Planejamento }\end{array}$ & $\begin{array}{c}\text { Negócios imobiliários financeiramente } \\
\text { viáveis. Validaçōes de negócios em curto } \\
\text { prazo. }\end{array}$ & $\begin{array}{c}\text { Avaliaçōes rápidas; } \\
\text { Ciclo de vida inteiro controlado; } \\
\text { Otimização de tempo; } \\
\text { Otimização de custo; } \\
\text { Controle e planejamento 3D; } \\
\text { Planejamento de fases; } \\
\text { Planejamento de utilização do canteino; } \\
\text { Análises e simulaçōes do canteino. }\end{array}$ \\
\hline Gerente de Projetos & $\begin{array}{c}\text { Projetos com alto nível de qualidade } \\
\text { (atendimento de diretrizes e boas práticas } \\
\text { consolidadas pela empresa) em tempo } \\
\text { adequado. Soluçōes e materiais } \\
\text { inovadores. }\end{array}$ & $\begin{array}{c}\text { Projeto aprimorado; } \\
\text { Coordenação aprimorada; } \\
\text { Comunicação aprimorada; } \\
\text { Otimização de tempo; } \\
\text { Análises e projetos de sistema de } \\
\text { construção; } \\
\text { Revisōes de projetos; } \\
\text { Autoria de projetos. }\end{array}$ \\
\hline Gerente de Produto & $\begin{array}{c}\text { Produto imobiliário adequado ao público } \\
\text { alvo definido pela empresa, dentro do } \\
\text { custo e valor de venda compatível com o } \\
\text { mercado de atuação. Produtos } \\
\text { diferenciados. }\end{array}$ & $\begin{array}{c}\text { Projeto aprimorado; } \\
\text { Autoria de projetos; } \\
\text { Ciclo de vida inteino controlado custos e } \\
\text { dados ambientais; } \\
\text { Modelagem de condição existente; } \\
\text { Validação de registros; } \\
\text { Melhor atendimento ao cliente. }\end{array}$ \\
\hline $\begin{array}{l}\text { Gerente de Qualidade e } \\
\text { Desenvolvimento } \\
\text { Tecnológico }\end{array}$ & $\begin{array}{c}\text { Obras com execução adequadas aos } \\
\text { procedimentos executivos e departamentos } \\
\text { com processos aderentes aos } \\
\text { procedimentos e às normas de referência. } \\
\text { Desenvolvimento Tecnológico, soluçōes } \\
\text { de materiais e novos sistemas construtivos, } \\
\text { com custo e desempenho adequado aos } \\
\text { padrōes da empresa. }\end{array}$ & $\begin{array}{c}\text { Validação de registros; } \\
\text { Análises e projetos de sistema de } \\
\text { construção; } \\
\text { Avaliaçōes rápidas; } \\
\text { Gerenciamento e rastreamento de locais } \\
\text { específicos do empreendimento. }\end{array}$ \\
\hline
\end{tabular}

Portanto, numa correlação entre um novo possível modelo de negócio, traduzido no Canvas abaixo, e os principais valores de entrega dos departamentos chave da incorporadora e construtora estudada, é possível perceber como um diferente processo de produção imobiliária aliada ao BIM, vai ao encontro dos grandes e determinantes anseios de valores para empresa estudada. Abaixo estrutura repensada. 


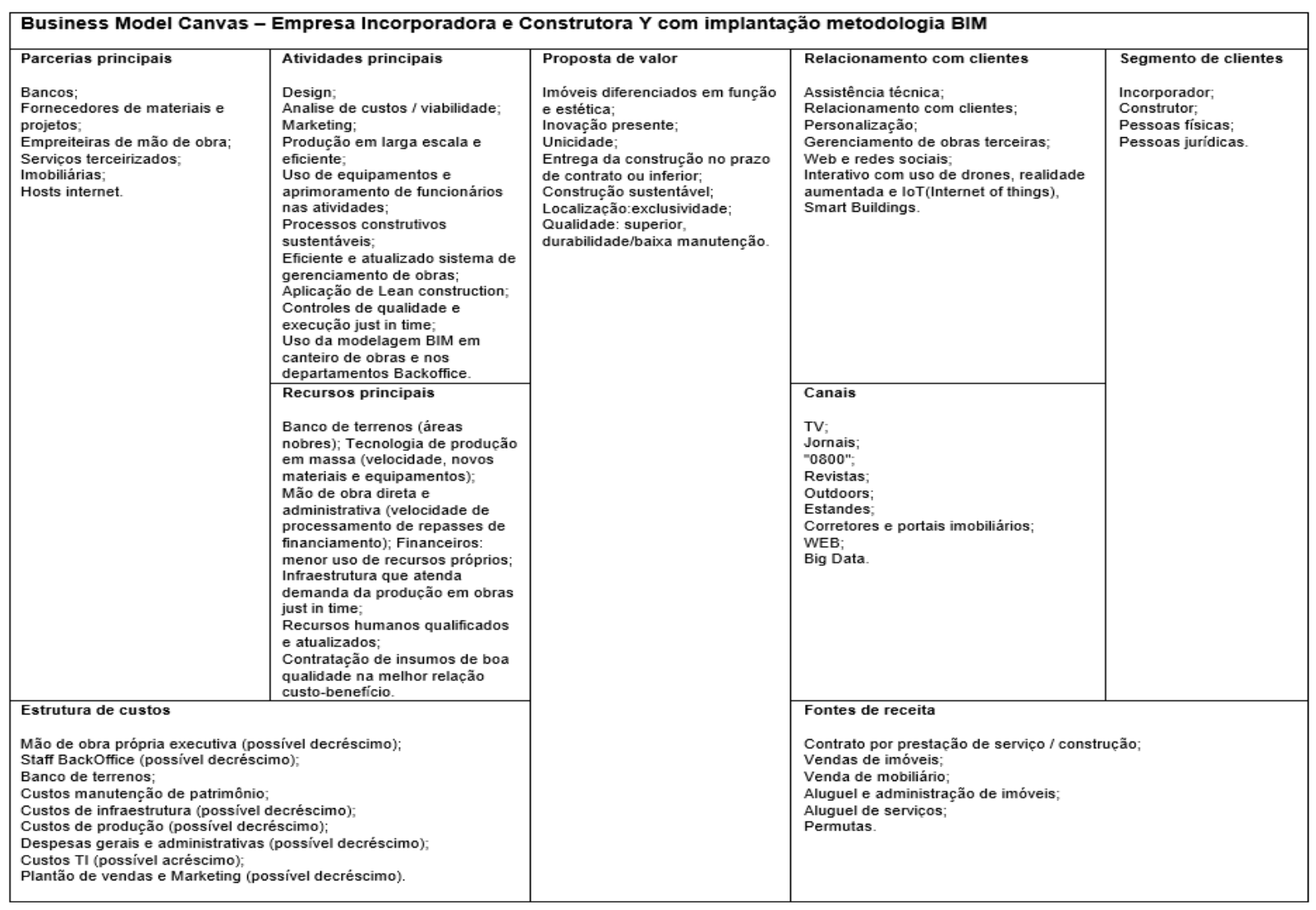

Figura 2: Proposta Business Model Canvas. Fonte: Autora.

\section{Considerações Finais}

A partir do estudo de caso em andamento e também referencial teórico, é possível afirmar que o BIM se apresenta como um portal com novas possibilidades para utilização de tecnologias e que tem potencial de promover mesmo em ambientes de inércia instaurada, tendências inovativas; somente pelo fato de se apresentar em representação de maneira indubitável. Como é o caso da utilização de drones, realidade aumentada, Iot (internet of things) e até Smart Buildings e Cities.

Quanto aos dados, considerado em dias atuais como o novo petróleo desta era, a utilização de Big Data e até mesmo sistema GED interativos, possibilitam arquivo fidedigno e analises "just in time". O grande anseio da melhoria na disponibilização da informação e da garantia dos fluxos de informações passa a ser tangível e já utilizado em outras indústrias.

Pode-se afirmar que a própria estrutura de custos se otimiza na nova proposta, o que possibilitaria melhora nas margens financeiras dos negócios. Neste sentido, BIM tende a abrir novas possibilidades como fonte de valor, uma vez que na modelagem podem-se se incluir novas interfaces, como de empresas de produtos e serviços.

Não há dúvida que desejos por diferenciação negociais podem ser tangibilizados com a presença da inovação em processos e possibilidade de unicidade em produtos imobiliários.

Com o mote principal de otimização e integração dos processos, o conceito BIM surge como alternativa eficaz no provimento da interoperabilidade, promovendo a necessária e hoje pouco 
eficiente conexão, encadeamento entre os agentes da cadeia produtiva da construção civil, garantindo por consequência maiores índices de produtividade para empresas incorporadoras e construtoras do setor imobiliário de modo sustentável.

Para adoção BIM, empresários do setor da construção civil deveriam iniciar o processo de implementação através da identificação dos benefícios tangíveis que justifiquem mudar seus processos de trabalho e a natureza de suas relações de negócios com parceiros e clientes. Após detecção destes, a implantação tende a render mudanças sistêmicas eficientes. Por consequência, as barreiras culturais, institucionais e comerciais, conseguem ser mais facilmente vislumbradas, planejadas e consequentemente superadas.

Por outro lado, enquanto a detecção de tais benefícios valiosos não for reconhecida e não estiver minimamente alinhada aos objetivos estratégicos empresariais, as mudanças tenderão a ocorrer muito lentamente e os obstáculos parecerão intransponíveis.

Portanto, pode-se afirmar que não se pode esperar que organizações clientes com relativo baixo grau de maturidade obtenham altos benefícios em negócios com processo de implementação do BIM, pois não necessariamente estariam aptos a desempenhar efetivamente suas funções BIM como organizações clientes, ação primária, em comparação com as organizações com nível de maturidade mais avançado.

A identificação das funções dos clientes no processo de implementação e seu relacionamento com as competências BIM, fornece diretriz crucial para a implementação na perspectiva do cliente, aumentando sua compreensão acerca da temática e sua capacidade de alcançar salutares benefícios almejados pela metodologia.

Ademais, irá auxiliar os clientes no desenvolvimento e aprimoramento das competências necessárias, ao invés de investir no desenvolvimento das competências que têm pouco ou nenhum impacto aos seus anseios como estratégia de negócio.

\section{Referências}

[1] A., Akhil, et al., "Critical success competencies for the BIM implementation process: UK construction clients." Electronic Journal of Information Technology in Construction. 24. $12,2019$.

[2] J. Barney, Firm resources and sustained competitive advantage, Journal of Management, vol. 17, no. 1, 1994.

[3] J. Barney, Is the resource-based "view" a useful perspective for strategic management research? Yes, Academy of Management Review, vol. 26, 2001a.

[4] P.M.P. Carvalho, "Análise Estatística do Estado de Implementação da Tecnologia BIM no Setor da Construção em Portugal." Faculdade de Engenharia da Universidade do Porto, Portugal, 2016.

[5] G.R. Jones, J.E. Butler, Costs, revenue and business level strategy, Academy of Management Review, vol. 13, no. 2, 1988.

[6] H. Mcgraw, "Construction. The Business Value of BIM in Australia and New Zealand: How building information modeling is transforming the design and construction industry." SmartMarket Report. EUA, 2014.

[7] H. Mcgraw, "Construction. The Business Value of BIM in North America: Multi- Year analysis and user ratings." SmartMarket Report. EUA, 2012. 
[8] A. Osterwalder, Y. Pigneur, Business Model Generation - Inovação em Modelo de Negócios: um manual para visionários, inovadores e revolucionários. Rio de Janeiro: Alta Books, 2011.

[9] B. Wernerfelt, “A Resource-based view of the firm', Strategic Management Journal , vol 5(2), pp. 171-180, 1984.

[10] R. L. Santana, et al., "Benefícios da monitoração de processos com BPM.” Tese de Doutoramento, Universidade Estadual do Ceará, Fortaleza, Brasil, 2011.

[11]B. Succar, Building information modelling maturity matrix. Handbook of research on building information modelling and construction informatics: Concepts and technologies, J. Underwood and U. Isikdag, eds., IGI Publishing, 2010.

[12] Yin, R. K. Estudo de caso: planejamento e métodos. Tradução Ana Thorell - 4. ed.- Porto Alegre: Bookman, 2010. 